\title{
As instituições de reclusão e "controle" dos loucos na Parahyba do Norte entre 1889 e 1928
}

\author{
Institutions of seclusion and "control" of the insane in Parahyba do Norte between 1889 and 1928
}

\author{
Edna Maria Nóbrega Araújo \\ https://orcid.org/0000-0003-2904-9695 \\ Universidade Estadual da Paraíba - Campus de Guarabira \\ Joedna Reis de Meneses \\ https://orcid.org/0000-0003-0385-9382 \\ Universidade Estadual da Paraíba - Campus de Guarabira
}

\begin{abstract}
Resumo: No final do século XIX e primeiras décadas do século XX a cidade da Parahyba do Norte, influenciada pelas ideias de modernidade e civilização, vivenciou uma série de reformas no espaço físico bem como diversas transformações nos costumes, hábitos e cotidiano de sua população. Essas reformas buscaram "retirar" e "excluir" das áreas centrais da cidade aqueles que eram tidos como responsáveis por promover a "desordem". Tratava-se de destruir desde edificações fora do chamado alinhamento e/ou excluir e, se possível, silenciar historicamente, os pobres, menores abandonados, mendigos e loucos que perambulavam pelas ruas. Neste artigo, se pretende estudar, especificamente, as tentativas de exclusão dos indivíduos considerados loucos das ruas da cidade da Parahyba do Norte, bem como a psicopolítica da exclusão. Para tanto, foram pesquisadas fontes como os Relatórios dos Presidentes de Estado/Província, Relatório da Santa Casa de Misericórdia e Jornais da época. Buscou-se historicizar as tentativas de controle dos ditos "furiosos" na Cadeia Pública, na Santa Casa da Misericórdia, posteriormente, no asilo Sant'Anna e, por fim, no hospital Colônia Juliano Moreira, quando os médicos psiquiatras puderam exercer um saber/poder nas instituições, pautados nos discursos científicos, que enclausurava, vigiava e silenciava os rotulados com a marca da loucura.
\end{abstract}

Palavras-chave: Loucura. Institucionalização. Enclausuramento. Cidade.

Abstract: At the end of the 19th century and the first decades of the 20th century, the city of Parahyba do Norte, influenced by the ideas of modernity and civilization, experienced a series of reforms in the physical space as well as several transformations in the customs, habits and daily lives of its population. These reforms sought to "remove" and "exclude" from the central areas of the city those who were held responsible for promoting "disorder." It was about destroying buildings outside the so-called alignment and / or excluding and, if possible, silencing historically, the poor, abandoned minors, beggars and madmen who roamed the streets. In this article, we intend to study, specifically, the attempts to exclude individuals considered crazy from the streets of the city of Parahyba do Norte as well as the psychopolitics of exclusion. Sources such as the Reports of the Presidents of State / Province, the Santa Casa de Misericórdia Report, and the newspapers of the time were searched for, trying to historicize the attempts to control the so-called "furious" in the Public Jail, at Santa Casa da Misericórdia, later Sant'Anna asylum and, finally, at the Colônia Juliano Moreira hospital, when psychiatric doctors can exercise knowledge / power in institutions based on scientific discourses. ficos, who cloistered, watched and silenced those labeled with the mark of madness.

Keywords: Madness. Institutionalization. Enclosure. City.

O tema aqui proposto tem o intuito de analisar os discursos sobre o louco na cidade da Parahyba do Norte entre 1889 e 1928, demarcando historicamente os momentos em que a Esta obra está licenciada sob uma Creative Commons - Atribuição 4.0 Internacional 
sociedade paraibana passou a intervir diretamente em seus corpos através de práticas de controle como a do enclausuramento hospitalar. É importante destacar que o louco passou a ser alvo de intervenção das autoridades governamentais no momento de consolidação de um projeto higienizador e civilizatório propagado pelo discurso modernizante presente nessa cidade. Tais mudanças vieram atreladas ao conceito de modernidade e foram construtoras de determinados discursos sobre loucos, pobres e mendigos, não apenas na cidade da Parahyba do Norte, como também em diferentes cidades ocidentais no mesmo período. Era um momento de reformas urbanas e de tentativas de exclusão dos indivíduos considerados não adequados às novas imagens das urbes.

Nesse sentido, os Presidentes de Estado e a Imprensa da época comentavam sobre a presença "incômoda" dos alienados nas ruas da cidade e a necessidade de serem "recolhidos". No período citado, os loucos costumavam ser enviados para a Santa Casa da Misericórdia onde viviam acorrentados, em péssimas condições de higiene, e conviviam com pessoas acometidas das mais diferentes doenças. Na cidade da Parahyba, os indivíduos considerados loucos também eram aprisionados na Cadeia Pública junto aos ladrões, bêbados, homicidas e estupradores. A partir de 1891, muitos passaram a ser internados no asilo Sant'Anna onde viviam em "cubículos escuros" sem higiene e sem assistência médica especializada e/ou minimamente adequada para um ser humano.

Com a fundação do Hospital Colônia Juliano Moreira, a experiência da loucura passou a ser "controlada" a partir de uma instituição específica na cidade. Esse controle, por sua vez, tinha um amparo teórico no saber da designada psiquiatria. Na instituição Juliano Moreira, as relações de poder foram postas em prática através das técnicas de disciplina e da docilidade empregadas aos corpos dos loucos. Produzia-se uma investida psicopolítica na qual esse saber, considerado científico, que alvejava os indivíduos e, devido ao internamento e às terapêuticas aplicadas, sujeitava-se as pessoas aos lugares de loucos e doentes. A partir de então, o internamento passou a ser considerado o artifício para o encontro da suposta "cura" dos males da mente humana.

O recorte temporal de 1889 a 1928, aqui proposto, inicia com a Proclamação da República e termina com a construção do Hospital-Colônia Juliano Moreira. Segundo Edvaldo Brilhante da Silva Filho (1990, p. 62) "de fato a história do 'Asylo de Sant'Anna' começou com a queda da monarquia e a eclosão do regime republicano (1889), que no campo jurídico foi a partir do Regulamento $n^{\circ} 169$ do dia 18 de janeiro de 1890. [...]". Meses depois, o governo do Estado deu sua autorização para o funcionamento das primeiras enfermarias específicas no tratamento dos pacientes psiquiátricos. Isso não significa dizer que há uma característica rígida e mecânica na consolidação do recorte cronológico, já que em várias ocasiões foi necessário fazer referência a momentos anteriores devido a importância de alguns aspectos para este estudo. Nesse sentido, pesquisar esse período é adentrar também na memória da cidade da Parahyba do Norte, nos discursos dos políticos, médicos, imprensa e instituições. É possível, assim, destacar a pertinência de se analisar a história do louco levando em consideração, principalmente, os seguintes problemas: entre 1889 e 1928, na cidade da Parahyba do Norte, teriam os conceitos de urbanização, modernidade, civilização e disciplina influenciado no cotidiano dos ditos loucos? Como a sociedade do período passou a observá-los e, principalmente, a intervir em seus corpos? Como foram produzidos os discursos sobre os loucos na cidade da Parahyba do Norte - João Pessoa nos anos de 1889 a 1928? Como viviam os loucos nas instituições totais na Parahyba do Norte? O que mudou no discurso médico em relação à loucura possibilitando a construção do Hospital Juliano Moreira em 1928?

$\mathrm{Na}$ busca pela análise destas questões iniciais foram pesquisadas fontes como os Relatórios dos Presidentes de Estado/Província, Relatório da Santa Casa de Misericórdia e Jornais da época. 


\title{
Cenários modernos da cidade e a criação das instituições asilares
}

A partir do final do século XIX e primeiras décadas do século $X X$, as cidades brasileiras, influenciadas pelas ideias de modernidade e civilização europeia, vivenciaram diferentes transformações, no espaço, nos costumes, hábitos e cotidiano da população. No citado período, transformar o mundo, mudá-lo, traduzia a ideia do que era ser moderno. Ser moderno era estar encantado com a modernidade, era se permitir demonstrar estar apaixonado com o que a sociedade urbana e industrial tinha trazido de diferente. Era se encantar com a velocidade do progresso, presente, por exemplo, nas estradas de ferro ou na produção industrial. Era buscar substituir práticas sociais antigas por novas. Portanto, ser moderno era, especificamente, buscar ser diferente do antigo, era estar preso ao sonho de transformar o mundo constantemente.

Desde o final do século XIX o sonho da modernidade vinha sendo compartilhado pela elite e intelectuais da Parahyba do Norte. Acompanhar a modernidade era o mesmo que estar apto para acompanhar o mundo, era preciso poder compartilhar com o mundo, como outras cidades brasileiras, a modernidade e o progresso. Esse desejo de acompanhar o mundo moderno não envolvia, portanto, apenas as grandes metrópoles, envolveu também as pequenas cidades (ARAÚJO, 2001).

As preocupações com a aparência da cidade eram denunciadas na imprensa:

\begin{abstract}
Nota-se que diversos passeios das principais ruas da cidade estão bastante estragados, havendo calçadas com grandes trechos sem tijollos. Esse desleixo dos proprietários, que concorre para afeiar a cidade e incommodar os transeuntes precisa ser corrigido pela coacção das posturas municipais. [...] Infelizmente ainda ha muita gente que não dá o devido apreço aquilo que é feito para o embelezamento da cidade. Tudo que diz respeito á vida civilizada desagrada aos inveterados hábitos da roça. Já é tempo de se corrigirem tantos defeitos incompatíveis com a vida civilizada de uma capital (A União, 26/10/1907, p. 01).
\end{abstract}

A citação acima, que data de 1907, menciona uma cidade que ainda não se "corrigiu". As últimas décadas do século XIX e início do século XX, porém, marcaram a cidade através da busca por esta correção. Em 1907 se falava em tijolos quebrados. Mas, desde 1866, por exemplo, buscava-se determinar como deveria ser construída a cidade, como deveriam ser colocados os tijolos. Ainda em 1866, observou-se a publicação de uma lei que estabelecia como deveriam ser construídas as casas na área urbana. Dizia a lei:

As fronteiras serão construidas conforme as posturas em vigor, terão cornija e calçada e serão rebocadas e caiadas. Os muros terão doze palmos de altura, [...] A calçada ou passeio quer nas fronteiras e muros, quer nas casas que se houverem de levantar ou reedificar será feito de conformidade com o nivelamento desta cidade (Edificações. Lei $243, \S 1^{\circ}$ e $2^{\circ}$." Collecção das Leis Provinciaes da Parahyba do Norte. Parahyba do Norte: Typ. J. R. da Costa, 08/10/1866).

As Posturas visavam eliminar o que se considerava irracional, ordenar as construções, controlar o espaço urbano. Estabelecer hábitos "civilizados". As pessoas foram proibidas de interferir diretamente no espaço que ocupavam com suas vidas e, em nome do alinhamento, do nivelamento, da estética das classes dominantes, não podiam mais decidir a forma de construção das suas casas, a largura das ruas, a altura dos muros, das fachadas, das janelas.

Entre o século XIX e início do século XX, as chamadas Posturas Municipais foram usadas, com frequência, como forma de esquadrinhamento urbano e como forma de controle dos hábitos $\mathrm{e}$ comportamentos do cotidiano da população. Além das posturas que demonstravam a ampla vontade de controle, muitas outras posturas se seguiram e estavam direcionadas não apenas para a rua, para as edificações, para os costumes, mas também impunham uma série de medidas referentes ao destino do lixo, ao arejamento das moradias, à limpeza dos armazéns, ao funcionamento dos açougues, aos depósitos de carne e peixe e de outros gêneros que facilmente se deterioravam, como as frutas e verduras. Ou seja: foram publicadas leis controlando lugares e 
ações que pudessem ofertar algum risco às condições de saúde da população (ARAÚJO, 2001).

Os governantes agiam, em nome da ordem, no sentido de disciplinar o uso da cidade, o comportamento dos seus habitantes e o corpo de cada morador da cidade. "Foi no biológico, no somático, no corporal que antes de tudo, investiu a sociedade capitalista. O corpo é uma realidade bio-política. A medicina é uma estratégia bio-política." (FOUCAULT, 1989, p. 80).

O encantamento que a modernidade provocava alcançou a elite política e intelectual da Parahyba do Norte. O governo gostaria de inovar, de modificar a cidade ou, precisamente, a sua estrutura urbana, de forma parecida com a das grandes metrópoles. Havia a expectativa de que a cidade estivesse caminhando nos trilhos da modernidade. E caminhar nesses trilhos significava apagar as imagens e os comportamentos do passado, encobrir os arranhões. Significava defender a remodelação da cidade. Nesse sentido, não se tratava de algo estranho para o Presidente de Estado, Camilo de Holanda, no ano de 1917, afirmar: "[...] em todas as construcções de direito administrativo, devemos copiar o que já se encontra feito e experimentado nos grandes centros evoluídos" (Mensagem apresentada pelo Presidente do Estado Sr. Dr. Camilo de Holanda. Parahyba do Norte, A União, 02/09/1917, p. 2, grifos nossos).

De acordo com Camilo de Holanda, percebe-se que as autoridades governamentais não apenas conheciam o que estava ocorrendo em outras cidades, como também queriam seguir seus exemplos. Através das matérias publicadas na imprensa do período, foi possível observar que os paraibanos estavam informados sobre as reformas urbanas ocorridas na Europa e em outras cidades brasileiras, uma vez que, nos próprios jornais, havia uma parte destinada às informações estrangeiras, sobretudo, acerca da França e da Inglaterra, além de outros espaços dedicados a cidades como o Rio de Janeiro, que representava o "maior centro cosmopolita da nação, em intimo contato com a produção e o comercio europeu e americano, absorvendo-os e irradiando-os para todo o país" (SEVCENKO, 1995, p. 28).

$\mathrm{Na}$ Parahyba do Norte, a influência europeia foi absorvida e, embora não tenha experimentado reformas modernizantes tão intensas quanto o Rio de Janeiro, não deixou de haver a tentativa de alinhamento aos padrões de civilização, progresso e desenvolvimento europeus. Estava em jogo um projeto de vida, um sonho do novo superar o antigo. As casas de taipa e os velhos casarões deveriam dar lugar a prédios novos, salubres, iluminados e bem arejados. As ruas estreitas e becos deveriam ser substituídas por ruas largas e avenidas, todas obedecendo às normas dos higienistas. A cidade perfeita teria que ter água encanada, energia elétrica, cinema, praças, bondes elétricos, entre outros aparatos que faziam da modernidade o desejo dos paraibanos mais abastados. A atuação dos Presidentes de Estado e Prefeitos da Capital demonstrava uma certa obsessão em construir uma cidade esteticamente moderna.

No início do século XX, acentuou-se a preocupação em reorganizar a cidade da Parahyba do Norte, que, aos poucos, teve seus espaços tradicionais de circulação, moradia, lazer e trabalho, redefinidos, remodelados. Destacaram-se, nessa busca de remodelação, os governos de João Lopes Machado (1908/1911), João Pereira de Castro Pinto (1912-1915) e Camilo de Holanda (19161920). No período desses governos, foram incentivadas e praticadas, dentre outras reformas, as seguintes: transformação dos logradouros públicos em locais atraentes através da remodelação, arborização e criação de praças e Jardins Públicos; derrubada das casas de palha, abertura de ruas e avenidas que visavam substituir os chamados becos insalubres; remodelação, caiação dos prédios públicos e calçamento das ruas. O projeto de rede de esgotos de 1913 também estava próximo aos elementos modernos que vinham sendo solicitados para a cidade, como a energia elétrica e o abastecimento de água. O ano de 1912, época do governo de João Machado, fora singular em relação a esses dois aspectos, uma vez que a Parahyba do Norte, a partir daquele ano, passou a contar com os serviços de água encanada e energia elétrica (ARAÚJO, 2001).

A rua e a casa ganharam, portanto, novos olhares, além do olhar do construtor. Foi preciso criar ruas largas, arejadas, bem ventiladas, com canais de drenagens, sistemas de esgotos e de 
abastecimento de água potável. As casas também receberam essa mudança de olhares e de vigilância: abrem-se janelas nas alcovas, varandas e terrassès modificavam a estrutura arquitetônica. Requeriam-se ambientes mais claros, mais ventilados, onde a luz do sol e o vento pudessem ter acesso livre, tanto quanto os membros aí residentes. Médicos, químicos e engenheiros opinavam sobre os melhores métodos de arejamento das cidades e das residências, e a salubridade tornou-se a base material e social capaz de assegurar a melhor saúde possível dos indivíduos. E é correlativamente à salubridade que aparece a noção de higiene pública, técnica de controle e de modificação dos elementos materiais do meio que são suscetíveis de favorecer ou, ao contrário, prejudicar a saúde (OLIVEIRA, 2003, p. 18).

Conforme Foucault (1989, p. 80), a medicina urbana contribuiu para o projeto modernizador das cidades e, na Parahyba do Norte, a influência da medicina fora de suma importância já que o apoio dos médicos, seja diretamente envolvidos na administração da urbes ou através dos seus discursos nos jornais, contribuiu para transformar o centro da cidade em um espaço ordeiro, asseado e belo, onde a elite pudesse transitar sem os perigos das doenças ou da incômoda presença dos pobres, mendigos, ladrões, menores abandonados, órfãos, loucos, aleijados e prostitutas. No entanto, é possível perceber na documentação pesquisada que, apesar das tentativas de exclusão e de construção de uma nova cidade, os pobres continuaram a disputar o espaço urbano com as elites. A velha cidade se encontrava com a nova. O brilho da moda, do moderno e dos novos costumes se via ofuscado pela presença de grupos sociais que não estavam disputando as melhores roupas, os melhores chapéus ou perfumes, mas o direito à existência que, evidentemente, não era silenciosa ou imperceptível como talvez desejassem os mais aquinhoados socialmente. Assim, de forma paralela às fachadas modernas que, naqueles dias, se buscava construir para a Parahyba do Norte, havia a miséria social em exposição permanente nas ruas da cidade (ARAÚJO, 2001).

A permanência dos pobres nos lugares públicos era tomada como um inconveniente, como um "espetáculo" deprimente, que causava tristeza e vergonha. A presença dos mendigos atrapalhava a imagem que se queria exibir da cidade.

Os atores nomeados por uma parcela da sociedade como mal-ditos e que compõem o cenário urbano são, em sua grande maioria mendigos, crianças abandonadas, enfermos, loucos, bêbados... sujeitos nômades que não tem outro lugar se não as calçadas e as ruas da cidade. Os memorialistas muito têm a falar sobre essas vidas errantes que vivem a compor a cartografia urbana. Vidas estas que são instituídas pela ordem moderna e civilizada como causadoras da desordem (BRITO, 2011, p. 36).

Como apresenta Brito, os pobres, loucos e vários outros que perambulavam pelas ruas, também eram considerados malditos na cidade de Campina Grande, eles representavam figuras contrárias à ordem da modernidade e da civilização que se desejava no momento. O que fazer para estabelecer a ordem urbana? Como excluir os indivíduos considerados atípicos das ruas e mudar a fisionomia da cidade para uma cidade ordeira, higiênica, civilizada e moderna?

$\mathrm{Na}$ cidade da Parahyba do Norte, entre o final do século XIX e as duas primeiras décadas do século $X X$, a solução encontrada para retirar os pobres das ruas estava na derrubada de suas casas de palha do centro da cidade. Já os doentes, velhos, mendigos e menores abandonados eram "escondidos" nos asilos e hospitais. Não havia preocupação com uma política para erradicar a situação de pobreza, mas, ao contrário, uma "defesa" cada vez maior da exclusão dos destituídos da cidade. Com isso, objetivava-se ocultar "das vistas do público, essa legião de seres imundos e repelentes" que "infestavam" as ruas (A União, 02/09/1917, p. 2). Mas, era necessário colocá-los em espaços específicos, onde aqueles que viviam do vício do roubo, da vadiagem e da mendicância pudessem se "regenerar" através do trabalho.

Visando essa eliminação e exclusão, foram criadas instituições assistencialistas, como os hospitais, o Instituto de Proteção à Infância e o Orfanato D. Ulrico, para abrigarem os menores, 
além do asilo da mendicidade, para recolher os mendigos:

Essa Instituição, que é uma das mais meritorias do Estado, realiza na Parahyba um grande ideal, qual seja o de plena assistencia aos necessitados-indigentes que dantes perambulavam pelas ruas, demindo-nos (sic), com o triste espectaculo da mendicidade, algumas vezes de pura exploração, os foros de cidade civilizada, além ainda de vários outros perigos de ordem moral e material. [...] A mensalidade dos sócios é apenas de mil réis, pagos semanalmente. Como se vê, a existencia do Asylo de Mendicidade da Parahyba importa em uma grande economia para cada familia, que dantes se via na contigência de soccorer semanalmente, a um grande numero de indigentes que lhe batiam ás portas [...] (A UNIÃO, 16/02/1917, p. 2).

A presença dos mendigos no perímetro urbano descaracterizava a pretensa imagem moderna e civilizada que a cidade da Parahyba do Norte desejava exibir para o mundo. Por isso, afastá-los significava uma dupla vitória. Primeiro, econômica, porque seria mais barato ajudar na manutenção de um asilo de mendigos do que atender-lhes os anseios cotidianamente, e, em segundo lugar, havia uma satisfação provocada pelo fato de que o "olhar" da elite não mais precisaria conviver com as imagens consideradas deprimentes, com certa desordem da cidade, o que justificava pagar para manter a cidade em "ordem", com os mendigos afastados.

O Asylo de Mendicidade, naquele momento, surgia como a instituição que seria capaz de promover, de forma rápida e barata, esse distanciamento dos mendigos das ruas da cidade.

Ao lado dos mendigos também caminhavam os loucos, e estes também eram considerados incompatíveis com a busca da modernidade. Eram pessoas que dependiam das esmolas ou de algum trabalho para sobreviver pelas ruas da cidade. Alguns, abandonados pela família, vagavam pelas ruas. "Tais personagens foram, em certa medida, tolerados nas cidades parahybanas por muitos anos. No entanto, quando eram acometidos por crises de excessos, se tornavam casos de polícia" (JUNQUEIRA, 2016, p. 108). Eram então encaminhados para a Cadeia Pública, ou para o Hospital da Santa Casa de Misericórdia ou para a residência familiar, onde eram mantidos presos nos porões ou quartos.

O que fica em evidência é que, na cidade da Parahyba, no contexto do século XIX, tal como aconteceu na Europa entre o seiscentos e o setecentos, conforme observou Foucault, a loucura só terá hospitalidade entre os muros dos hospitais e/ou das cadeias, junto aos pobres e indesejáveis. E aqui, como lá, também se observou uma degradação moral da pobreza, antes vista sob a sigla da misericórdia e que passou a comportar todos os tipos de práticas antissociais (JUNQUEIRA, 2016, p. 110).

Sobre a prática de confinar loucos e pobres, de forma vinculada, nos hospitais é interessante lembrar Foucault quando chama atenção para o momento da grande internação:

Uma data pode servir de referência: 1656, decreto da fundação, em Paris, do Hospital Geral. 'A Casa e o Hospital tanto da grande e da pequena Misericórdia quanto do Refúgio, no bairro de Saint-Victor, a Casa e o Hospital de Cipião, a casa da Savonnerie, com todos os lugares, praças, jardins, casas e construções que deles dependem'. Todos são agora destinados aos pobres de Paris, 'de todos os sexos, lugares e idades, de qualquer qualidade de nascimento, e seja qual for sua condição, válidos ou inválidos, doentes ou convalescentes, curáveis ou incuráveis. (FOUCAULT, 2005, p. 49).

Nesse sentido, observa-se que o Hospital Geral foi um espaço para recolher o pobre, o miserável e o que não "pode responder pela sua própria existência" na cidade. O Hospital Geral não possui nenhuma associação com a ideia médica de cura como a enunciada nos dias de hoje. É uma "estrutura semijurídica, uma espécie de entidade administrativa que ao lado dos poderes já constituídos, e além dos tribunais, decide, julga e executa” (FOUCAULT, 2005, p. 50).

Os loucos, durante um século e meio, foram colocados sob o regime desse internamento, até que foram libertados das salas do Hospital Geral, por Pinel, Tuke e Rush, respectivamente na França, Inglaterra e Estados Unidos. Eles foram os "pioneiros de um movimento reformista no 
tratamento dispensado ao louco, possibilitando a construção de locais específicos para a internação, nos quais ele passaria a receber algum tipo de cuidado" (OLIVEIRA, 2008, p. 21).

Michel Foucault, em História da Loucura (2005), chama a atenção para o grande internamento ocorrido na Europa no século XVII. Na Parahyba do Norte se pôde observar o recolhimento dos também chamados perigosos no século XIX, principalmente na Santa Casa de Misericórdia onde pessoas acometidas de diferentes doenças eram internadas no mesmo espaço.

A existência de loucos e/ou loucas na Parahyba não é recente. No entanto, somente em 1830, por meio da Postura Municipal $N^{0} 10$, foi que se ouviu o primeiro grito sobre as experiências da loucura na Província da Parahyba. Depois disso, em 1858, quando governava a Província o Sr. Henrique Beaurepaire Rohan, foi que a existência desses sujeitos veio à luz. Naquele ano, o provedor da Santa Casa de Misericórdia da Parahyba, o Sr. Francisco d'Assis Pereira Rocha, tentou, um movimento, muito semelhante em seus fins, àquele representado pela experiência da Nau dos Loucos, qual seja: livrar, não só a Província, mas, principalmente, aquela Casa de Caridade, do "terrível fardo", representado pela responsabilidade de recolher e cuidar dos(das) alienados(as). Indignado, o Provedor Pereira Rocha reclamava da proibição de enviar para o Hospício Pedro II, no Rio de Janeiro, os alienados que viviam divagando pelas ruas de Parahyba.

Em 1828, os Loucos e /ou as loucas já não eram aceitos(as) quando circulavam pelas ruas da cidade e, em 1858, a situação era mais complexa diante do desejo das autoridades de enviá-los para o Rio de Janeiro onde deveriam ficar internos no Hospício Pedro II, recém-criado pelo Imperador. Diante da não autorização por parte do Imperador, o Senhor Pereira Rocha se mostrava bastante descontente, já que os loucos continuariam na Santa Casa de Misericórdia dividindo espaço com outros doentes.

Por outro lado, o Dr. Innoccencio João José Poggi em seu Relatório como Provedor de Saúde da Província, sugerira construir um lugar específico para os alienados "de modo a resistir aos estragos que eles costumão praticar, e que os livre o mais possível dos choques, contusões". (POGGI, 1858, p.3).

Felizmente a segunda dessas urgentes necessidades vae ser satisfeita no andar térreo da nova obra da enfermaria das mulheres, e talvez a primeira também possa sê-lo. Segundo consta, no pavimento inferior do Hospital da Santa Casa, foram edificadas saletas, arejadas com grades de ferros nas janelas, destinadas aos alienados[as], que, logo que concluída, teve outro destino, dado ao fato de ter aparecido demandas consideradas mais "uteis"”. Os loucos e/ou loucas permaneceram confinados no pavimento térreo, nas duas celas sujas e escuras nos fundos do Hospital, junto à cozinha onde tantas vezes estiveram de mistura com os presos, "e por baixo do salão, em que se ach[avam] as enfermas, de sorte que, quando se ach[avam os loucos e/ou loucas] nos intervalos de furor não pod[iam] as enfermas tranquilizar[em-se] um instante". (NEVES, 1862, p. 2)

A insatisfação ou indiferença dos dirigentes da Santa Casa em relação aos loucos pode ser observada quando o espaço antes destinado a eles fora utilizado para outros fins, dito "mais uteis".

Passavam-se os anos e, ao que parece, a insatisfação diante da permanência dos loucos na Santa Casa de Misericórdia só aumentava, como também aumentava a violência com que eram tratados:

Chegado à década de 70 do século XIX, a Santa Casa encontrava no argumento da falta de espaço uma forma de se ver livre dos "indesejados" hospedes, que, conforme referido pelo Provedor Joaquim Moreira Lima, "não só perturba[vam], e encommoda[vam] os outros doentes [e também os funcionários do estabelecimento], como arruína[vam] e destro[iam] o edifício", diante do que, converia ao menos, já que não se pode fazer um edificio independente, preparar alguns quartos com toda a segurança para esses infelizes. Conservos em ferros, e algemados para evitar que eles arrombem os quartos, é um crueldade pungente. Não existe no Hospital uma só prisão segura, e com as comodidades indispensáveis a esses enfermos. Se a Assembléa não der os meios os infelizes teram de sofrer, além dos encommodos d'essa cruel enfermidade, as violências empregadas para conte-los (JUNQUEIRA, 2016, p. 122-123). 
Indesejados por todos, médicos, funcionários, e até mesmo pelos familiares, em decorrência do seu comportamento, eles recebiam um tratamento desumano. Eles viviam "conservados em ferros, e algemados" como se aprisionados nas salas.

De acordo com Edvaldo Brilhante da Silva Filho, o aprisionamento já era uma prática utilizada em relação aos loucos ao longo do período colonial e do período imperial, associado a outros recursos terapêuticos considerados "não científicos":

Há registros que os insanos muitas vezes recebiam severos castigos físicos, pois era uso corrente pensar tratasse de problemas de possessões demoníacas (questões espirituais), também usavam medicações caseiras como chás de ervas medicinais, os banhos de água quente e fria, os banhos de mar, as orações das benzedeiras (conhecidas por rezadeiras), tinham ainda os exorcismos (praticados pela Igreja Católica), os enclausuramentos radicais, onde os mais agressivos eram acorrentados trancafiados dentro de cubículos nos porões das residências, etc. (SILVA FILHO, 1998, p. 44).

Ao longo dos anos, os loucos que não perambulavam pelas ruas sofriam em suas residências. Eram as próprias famílias que os escondia nos porões escuros. Quando era possível, enviavam-nos para instituições onde ficavam reclusos ou, usando a terminologia usada por Erving Goffman (2005), instituições totais. Nesse sentido, os loucos foram "fechados" em várias instituições e com os mais variados grupos de sujeitos, sejam em hospitais destinados a doenças contagiosas como a Santa Casa, nas Cadeias Públicas, dentre outras. Junto com essa contingência de sujeitos, os loucos passaram a ser, aos poucos, silenciados, pois foram misturados aos criminosos e aos doentes de variadas patologias.

Na Parahyba do Norte, uma das principais instituições a desempenhar o papel de instituição total foi a cadeia pública. Embora pouco explicitado em seus relatórios, apresentados aos presidentes de Estado, constata-se que a cadeia pública foi grande receptora de loucos, como mostra o relatório abaixo:

O digno chefe de policia em se o minucioso relatorio referindo-se à Cadeia desta capital, disse n'ella existirem 107 presos, numero excessivo que o edificio não comporta, sendo precizo para evitar tal aglomeração que os Srs. Juizes das diversas circumscripções do Estado não enviarem presos indiciados, apellados ou protestado. O honrado Dr. Chefe de policia reclama em seu relatorio providencia no sentido de serem effectuados certos melhoramentos no edificio que serve de cadeia publica nesta capital é justo que algo se faça para dar melhores e mais hygienicas accomodações ao velho edificio, onde se acham reclusos quase todos os sentenciados do Estado. Pelos mappas constantes do relatorio da policia vê-se que do $1^{\circ}$ de Setembro do anno passado até Julho ultimo, entraram na cadeia publica da capital 152 presos, sendo que a 23 de Julho existiam na mesma prisão os seguintes crimes: de homicídio - 47 roubo -17 estupro -3 ferimento -7 defloramento -1 moeda falsa -1 alienados -2 (LEAL, 1906, $p$. 6)

Outros exemplos: "Notas da Polícia dia 10 existiam na cadeia 222 presos, sendo 220 criminosos e 2 desordeiros. Existem mais duas mulheres alienadas". (Estado da Parahyba 13/11/1891, p. 2). Outro Jornal também afirma: "Existem recolhidos a cadeia 163 detentos sendo 6 alienados." (Correio Official, 15/01/1903, p. 2).

Como apresentado nos relatórios, os alienados eram encarcerados com os mais variados detentos, acusados de vários crimes, de roubo a homicídio. Percebe-se, então, que nesse período citado, a imagem do louco ainda estava sendo construída enquanto doente.

Diante do exposto, pode-se observar que a cadeia pública era uma das principais instituições que enclausuravam os sujeitos tidos como loucos. Todavia, considerando os demais relatórios do Presidente de Estado, pode-se verificar um significativo silenciamento nos respectivos documentos sobre a presença dos loucos na cadeia, ou sua pouca menção. No entanto, outros indícios fazem perceber que o número de loucos presos nessa instituição era muito maior do que os esporadicamente divulgados. O que aponta para tal direcionamento são as inúmeras notícias 
divulgadas no periódico $A$ União, onde trazia constantemente os nomes dos indivíduos que foram presos por "distúrbio" ou por "parecer sofrer de doença mental", conforme se pode observar nos seguintes exemplos: "Durante o policiamento de ante-hontem para hontem, por guardas civis, foi recolhido a Cadeia Publica o individuo Antonio Pereira de Carvalho, que apresentava symptomas de loucura" (A União, Parahyba do Norte, 05/11/1915, p. 2). "[...] deu entrada nesta cadeia [...] a mulher Maria Alexandrina da Conceição, que se achava sofrendo de alienação mental”. (A União, Parahyba do Norte, 25/11/1924, p. 3). "O Guarda de n. 68, de serviço na praça Vidal de Negreiros, conduziu á Repartição Central de Policia o individuo Virginio Teixeira, por parecer soffrer das faculdades mentaes". (A União, Parahyba do Norte, 08/12/1929, p. 3). "O guarda ${ }^{\circ}$ 60, de serviço na praça da Independencia, conduziu a policia o individuo Chrispiniano Nunes, por parecer soffrer das faculdades mentaes." (A União, 26/02/1930. p. 2). Os dados expostos no Jornal $A$ União nos fazem concluir, mais uma vez, que a cadeia pública era uma das instituições que mais encarceraram os sujeitos tidos como loucos.

Se existiam quase diariamente pessoas presas como loucas, como justificar os Relatórios de Presidente de Estado com um pequeno número de presos? O que classificaria estas pessoas como doentes mentais? Como elas se apresentavam para receber tal diagnóstico e serem levadas para a delegacia? Qual o conhecimento teria o Guarda de número 60 ou 68 para identificar um louco? Como eles eram tratados na prisão?

É importante pensar as prisões como instituições disciplinares, como instituições que estavam preocupadas com as chamadas pessoas perigosas, inclusive com os loucos, no sentido de retirá-los das ruas.

Desta forma, tratar a questão da loucura nas instituições de segurança da cidade da Parahyba do Norte leva, inevitavelmente, para a problemática de sua invisibilidade. No entanto, essa invisibilidade discursiva em torno da loucura e do sujeito louco produz também uma outra forma de controle e de sujeição a qual este artigo tem buscado analisar, ou seja, o silenciamento dos indivíduos a partir da psicopolítica. A partir desse momento histórico, começa a se produzir um cenário de exclusão e, por conseguinte, de silenciamento uma vez que o pensamento dos indivíduos considerados loucos historicamente tem sido ignorado.

No final do século XIX e início do século XX, a história deste silenciamento, desta invisibilidade, começou a ser construída, principalmente com as diferentes tentativas de naturalização do aprisionamento dos loucos. Por exemplo, diante da falta de instituições para receber os loucos e, considerando que em Recife e Olinda já existiam espaços específicos a eles destinados, a comparação com essas cidades vizinhas era constante naquele período. Essa comparação, que naturalizava demasiadamente a ideia de um espaço específico para o enclausuramento dos loucos, resultou em uma campanha pela criação de um novo hospital para eles. Na Santa Casa, principalmente, nos momentos em que havia possibilidade de seca ou epidemias, a campanha se acentuava. Nesse sentido, no ano de 1890 foi inaugurado o primeiro estabelecimento para o "recolhimento" dos doentes mentais na cidade da Parahyba do Norte, o Asilo Sant'Anna (SILVA FILHO, 1998). Não se tratava de um asilo no modelo "científico", mas um lugar onde pudessem recolher os loucos retirados das ruas. Como bem colocado por Castro (1945, p. 366): “[...] os insanos passaram a contar [...] com um tecto e não hospital, um verdadeiro deposito humano, onde se recolhiam"1.

Os primeiros doentes mentais do 'Asylo de Sant'anna' vieram trazidos para tratamento especializado da famosa Cadeia Pública da capital, pois encontravam-se recolhidos (como

\footnotetext{
1 O terreno do Asilo Sant'Anna foi comprado em 1859, pelo Presidente Henrique Beaurepaire Rohan para abrigar o Colégio de Educação de Artifices da Paraíba e foi extinto em 1875. Já em 1878 diante do surto de varíola, "este foi transformado em Hospital dos Variolosos", já que ficava distante da cidade. "Finalmente com o passar dos anos este foi servido para abrigar toda sorte de pessoas marginalizadas socialmente, como os doentes de outras endemias: cólera, febre amarela, tifo, sífilis," etc. e até os pobres juntos retirantes vítimas do flagelo da secas de 1877-1879, mendigos comuns ou vadios, prostitutas e muitos outros [dentre eles os loucos] (SILVA FILHO, 1998, p. 61-62).
} 
prisioneiros comuns) já que esta era uma atitude bastante normal para a época. Chegaram inicialmente '12 loucos furiosos' para ocupar os doze quartos (tipo cubículo individual) que existiam no local, eram divididos em 06 quartos para homens e 06 para mulheres. (SILVA FILHO, 1998, p. 63).

O Asilo Sant'Anna foi o primeiro hospital específico para loucos na Parahyba. E, a princípio, recebeu os presos tidos como "loucos furiosos" para ocuparem os pequenos quartos daquele hospital. Porém, diante das condições descritas por Oscar Oliveira Castro, a situação dos loucos parece não ter sofrido mudanças significativas ao deixarem a Cadeia Pública:

Era um pavilhão colocado ao lado nascente do atual Hospital Santa Isabel, baixo, com mais ou menos uns trinta metros quadrados de área coberta. O edifício, além da alpendrada que o rodeava, dispunha de 12 celas escuras e sem ventilação, cujas portas, únicas e pesadas singularizam-se pelo orifício de forma retangular, bem no centro, com grade de ferro em forma de cruz, atestando o perigo do excitado, cujos gritos desordenados, ecoavam além do alto muro que o separava do mundo exterior. Por aquele arremedo de janela, escavado na porta processava-se toda a comunicação do insano com o Enfermeiro ou pessoas da família. A passagem de medicamentos e refeições se fazia através daquelas grades frias e impassíveis. No piso de cada cela, bem no centro existia o orifício da fossa, cujos gases nauseabundos enchiam o recinto (CASTRO, 1945, p. 366).

O que se observa nesse período sobre a experiência da loucura na Parahyba do Norte, é um enclausuramento, ou seja, o internamento dos loucos, em condições desumanas. Sem receber tratamento ou atenção dos profissionais da área de saúde. O que mudaria na vida dos loucos que saíam dos porões de suas casas ou das prisões e ficavam meramente presos dentro dos cubículos de um Hospital? Portanto, o tratamento, a busca pela cura ou bem-estar do interno e sua reinserção em sociedade não era algo imaginado naquele período. O que fica evidenciado é a necessidade de prender, enclausurar sem um sentido para além da palavra enclausuramento ou controle. Como considera Foucault, "O internamento seria assim a eliminação espontânea dos 'a-sociais' [...]” (2005, p. 79), portanto, o internamento na capital da Parayba só serviria para a eliminação dos loucos do espaço urbano.

$\mathrm{Na}$ descrição da estrutura do Asilo Sant'Anna, fica claro que a preocupação desse estabelecimento não era pautada em uma terapêutica ou em uma ideia de tratamento e cura, era, sobretudo, um regime de internamento fechado, longe das ideias "humanísticas" (de tratamento) da psiquiatria que eram derivadas das ideias desenvolvidas até mesmo por Pinel ${ }^{2}$. Pode-se perceber, nesse momento, a ausência do que Foucault chamou de relação poder/saber referente ao médico psiquiatra no asilo Sant'Anna, pois o campo psiquiátrico ainda não existia na Parahyba.

Como apontado, o Asilo de Sant'Anna já nasce com fortes problemas de estrutura e de tratamento especializado para esse tipo de enfermo. Castro, ao discutir as formas de terapêuticas empregadas nessa instituição, expõe que os enfermeiros exerciam mais participação no cuidado com os pacientes que os próprios médicos. Além disso, argumenta que as visitas dos médicos, à Santa Casa de Misericórdia, eram muito rápidas. Nesse aspecto, "A terapêutica se resumia na aplicação de calmantes, brumuretos e mais brumuretos, cujo efeito medicamentoso era secundado pela reclusão" (CASTRO, 1945, p. 367).

Para além desse problema, outro se mostrava preocupante: a falta de espaço e leitos para a grande demanda de indivíduos que pleiteavam um, e vale ressaltar que o Asilo Sant'Anna era responsável pelo recolhimento de doentes de várias partes do estado. O asilo contava com 12 salas, contudo, o número de asilados extrapolava, em muito, essa quantidade: "Identificamos em janeiro do ano de 1895 uma população de 40 asilados, sendo, nesse caso, 28 internos a mais que sua capacidade". (A UNIÃO, 1895, p. 1).

\footnotetext{
2 "Assim como Pinel, no final do século XVIII, os primeiros alienistas brasileiros reivindicaram para si [...] o tratamento humanitário dos doentes." (CUNHA, 1989, p. 45).
} 
Em resposta a essa problemática, não demorou muito para que o Asilo Sant'Anna passasse a ser objeto de inúmeras críticas, principalmente vindas da impressa, que, nesta época, passava a se preocupar com a organização espacial da cidade e, sobretudo, do conhecimento médico, que aos poucos ia se constituindo enquanto autoridade na remodelação da cidade. Data do ano de 1897 a primeira reclamação referente a essa instituição, no ofício do major Mariano Rodrigues Pinto, pedindo providencias do presidente de Estado, Antonio Alfredo da Gama e Mello, junto àquele estabelecimento:

$\mathrm{Na}$ tarde do dia 6, visitei o Asylo de Sant'Anna, installado no sitio Cruz do Peixe, fazendo-me acompanhar pelos irmãos Escrivão, Procurador Geral e Mordomo respectivo. É indescriptivel o estado desse estabelecimento, onde se acham recolhidos os alienados e os doentes de enfermidades contagiosas.

Os cubículos occupados pelos alienados [...] acham-se todos humedecidos e resfriados em consequencia do gotejamento geral da coberta dos edifícios na presente estação chuvosa. As roupas, de que se servem os doentes actualmente, são escassos e repugnantes andrajos que, dados a consumo no hospital de Santa Izabel, são remettidos para ali, a de vestir os infelizes enfermos, que não dispõem de muda, quando estes vão a lavanderias, conforme fui informado pelos respectivos enfermeiros.

Falta-lhe também roupas, louças, asseio e até as condições hygienicas necessarias á estabelecimentos daquella natureza; do que resulta que alguns doentes longe de encontrarem alivio e o restabelecimento de suas enfermidades, muitas vezes adquirirem novas, que os levam a seputura. (A UNIÃO, 17/07/1897, p. 1).

Em 1910, com a chegada do Dr. Octávio Ferreira Soares, começou o que Edvaldo Brilhante chamou de fase científica da Psiquiatria na Parahyba, (1998, p. 68) uma vez que o referido médico possuía uma formação em psiquiatria na Faculdade de Medicina do Rio de Janeiro e passou a trabalhar no Asilo Sant'Anna.

No entanto, a documentação mostra que não ocorreram mudanças na forma de tratamento dos loucos internados no Asilo Sant'Anna. Em 1913, o relatório do presidente João Pereira de Castro Pinto deixa bem claro que o mal-estar causado pelas condições em que se encontrava a população interna dessa "casa de supplicios" continuava:

Se todos os serviços de caracter official ou não, mas affectando à comunhão alcançassem a bem-aventurança de uma superitendencia tão conduzida como a do talento magistrado na Santa Casa de Misericórdia, nós teríamos recuperado meio século de atraso em nossa evolução social, rememorada pela differença e pelo egoísmo, pelos erros e pelas faltas secresivamente accumulados.

Prova desta minha asserção está ali, no hospício de alienados, antro de miséria e de angustias, onde recolhe os loucos para mais inremediavelmente se lhes desenvolver a louca, em taes condições de hygiene que parece uma casa de supplicios, cuja planta, e cujo regime nos viesse da China. (PINTO, 1913, p.44)

Os discursos promovidos sobre as condições do recinto ou das formas de tratamento, tornaram-se cada vez mais notáveis e presentes nos meios da imprensa e entre as autoridades governamentais.

A questão publica e social da assistencia aos allienados ainda é lettra morta na Parahyba do Norte, talvez por um descaso injustificavel dos seus govêrnos. O que nós aqui temos - 0 ergastulo da Cruz do Peixe - é uma masmorra infecta e sem luz, mais propria e enloquecer os sadios que a asylar esses pobres doentes do systema nervoso. Aquella baiuca lugubre, de portas negras, com pequenos guiehéts guarnecidos de ferro era e é em tudo proporcional ao que chamavamos emphaticamente de Cadeia Publica, deshonrando as modernas instituições do Direito Penal [...] (Diário do Estado. Parahyba do Norte, 28/02/1919, p. 2).

E ainda:

A construção da Colônia de Alienados tem despertado causas criminosas com a Santa Casa 
porque tem mantido esse Serviço de assistência aos loucos. Os censores esqueceram que foi o Estado que fez construir em 1890 o prédio que reclusa os destituídos da razão, o entregando a Santa Casa em 1893, em condições inferiores as atuais. Felizmente está próximo o término desse Serviço para Santa Casa, e para os loucos, que não tem um tratamento ditado pelos últimos ensinamentos da ciência médica. (NOVAES, 1925, apud SILVA FILHO, 1998, p. 65, grifos nossos).

Esses discursos passaram a ser promovidos, majoritariamente, a partir da segunda década do século XX, principalmente, depois da criação do órgão da "Repartição de Hygiene" durante o governo do presidente João Lopes Machado. No entanto, apesar de demonstrar a repetição, ano após ano, das mesmas reclamações em relação às precárias condições do Asilo Sant'Anna, não fizeram nada para mudar. Apenas criticavam e os loucos continuavam lá.

Esses dois aspectos, criação da Repartição de Hygiene e o governo de João Lopes Machado, são importantes para entender porque esse período passa a sofrer a investida do discurso médico referente ao tratamento desses doentes mentais. A Repartição de Hygiene foi responsável por organizar um saber/poder junto à classe médica, fazendo-os ter maior participação frente à população (SANTOS, 2015). O que estava implícito era a participação e constituição do médico enquanto um agente de transformação social, o profissional que detinha a chave do progresso e do desenvolvimento. Era o portador da cura e do saber científico.

Outro fator de importância é que os médicos passaram a compor os meios políticos e da imprensa na cidade da Parahyba e, nesse sentido, percebe-se que os olhares para os modelos higiênicos e sanitaristas tornaram-se reivindicações bem mais fortes do que em momentos anteriores. Os médicos, aos poucos, começam a sair de seus consultórios e hospitais para ocupar outros postos no governo, principalmente posições de destaques nos serviços de saúde. Além dos mais, os altos segmentos da urbe paraibana, desejosos do progresso e da civilização, elegeram o discurso médico-sanitário como o caminho pelo qual remodelariam a cidade e construiriam uma Parahyba nova, moderna, limpa e educada. Aos médicos fora dado o poder reformador (SANTOS, 2015).

Portanto, fica claro que o asilo Sant'Anna, era um estabelecimento que não se adequava a essa nova lógica de internamento asilar dos doentes mentais. Com o advento do regime republicano, como aponta Cunha (1989), uma nova lógica de tratamento para com esses sujeitos nascia. Não mais seria útil apenas trancafiá-los em salas úmidas e deixá-los aos cuidados de enfermeiros, sem médico especialista, ou seja: o psiquiatra.

É importante notar, que embora os discursos de ataque ao asilo Sant'Anna, sejam, na maioria das vezes, mascarados pelo caráter humanista e assistencialista, eles traziam em suas entranhas toda uma lógica de disciplina e uma apropriação desses indivíduos através das práticas discursivas advindas do saber psiquiátrico. Portanto, o campo psiquiátrico da Paraíba precisava de um estabelecimento que se adequasse a esse padrão estabelecido pelo conhecimento científico, porque, como afirma Foucault em Microfísica do Poder (1989, p. 28), o hospital não se caracteriza apenas como uma "máquina de curar", mas, sobretudo, como um instrumento que serve para "[...] produção, acúmulos e transmissão de saber."

Dialogando com Michel Foucault no texto "A casa dos loucos", percebe-se que o asilo Sant'Anna não se assemelhava aos asilos instituídos durante o século XIX, principalmente na Europa, pois, como trabalhado por aquele autor, o asilo do século XIX desempenhava um papel de lugar de "diagnóstico" e "classificação". Era, sobretudo, um "[...] espaço fechado para um confronto, lugar de uma disputa, campo institucional onde se trata de vitória e submissão" (FOUCAULT, 1989, p. 203). Ou seja, o médico dessa instituição estava construindo uma relação de poder e saber implicado na observação e classificação desses indivíduos: só ele poderia dizer a "verdade" sobre eles, acarretando uma apropriação do sujeito louco pela medicina e pelo hospital, o que obviamente não caracterizava o asilo Sant'Anna.

Além da falta de assistência especializada no asilo Sant'Anna, também faltava vaga para 
receber os loucos que procuravam o hospital em busca de atendimento:

A Provedoria dessa instituição faz ciente que os hospitaes de Santa Izabel, Sant'Anna e a enfermaria dos loucos estão completamente cheias, não havendo espaço para colocar uma esteira, e por isso deixa de admitir doentes nos mesmos enquanto não houver vaga. (Diário do Estado. Parahyba do Norte, 28/02/1919, p. 2).

Os loucos não podiam circular nas ruas, como também faltava vaga nos hospitais da cidade que eram destinados aos alienados. Essa situação era frequentemente retratada nos jornais que criticavam não só a falta de hospitais, mas as condições de funcionamento dos existentes.

Nesse sentido, políticos e médicos passam a investir na construção de um novo hospital para loucos, como foi observado na documentação consultada, onde consta a presença de correspondências entre o Presidente Camilo de Holanda e o psiquiatra Dr. Juliano Moreira "pedindoIhes conselhos technicos" e "soccorrendo-se das luzes" do psiquiatra. (A União, 1917, p. 3).

No ano de 1918, o médico psiquiatra Octávio Ferreira Soares, fazendo uso da imprensa, veio a público pedir apoio ao governo de Camilo de Holanda no tocante a assistência desses "infelizes alienados", em um artigo intitulado "Assitência de Alienados":

[...] o nosso asylo Cruz do Peixe se acha sempre com os cubículos cheios de doentes, porque, os parentes e a policia, embora reconheçam a insalubridade, o horror do edifício[...] E o que fazer ao ver semelhante espectaculo? Nada! Cofranger-se-nos e recolhel-os, pois a sociedade e os parentes os repellem! E para quem appellar?

Para o exmo. sr. dr. Camillo de Hollanda, medico distincto, conhecedor de todos os segredos da sciencia moderna, viajado, o qual reconhece a necessidade de tal serviço tão utilitário á collectividade, e que perpetuará o seu nome no torrão natal. (A União, 15/06/1918, p. 4)

O discurso do médico Octávio Ferreira Soares, foi mais um discurso proferido em favor da construção do Hospital Psiquiátrico e, percebe-se que, na medida, que o então médico, fez referência à situação em que se encontravam os doentes no asilo Cruz do Peixe, propiciou também uma cobrança para a fundação de um hospital para os loucos na cidade.

Já no ano de 1917, Octávio Ferreira foi enviado em uma excursão ao Rio de Janeiro, para ter com o psiquiatra Juliano Moreira, para assim buscar os mais novos conhecimentos referentes à ciência psiquiátrica. $E$ foi nesse modelo de psiquiatria e internamento asilar defendido por Juliano Moreira que o Hospital para doentes mentais foi pensado e construído em solo paraibano.

Porém, foi no ano de 1928 que se deu a inauguração do Hospital-Colônia Juliano Moreira, cujo objetivo era abrigar os alienados em um local que realmente fosse exclusivo para os tratamentos que eles precisavam; ao menos essa era a justificativa a qual rendeu aplausos na semana médica da Parahyba:

O Dr. Sá e Benevedes traçou longamente a história do hospital Colonia Juliano Moreira conseguido para nossa terra no govêrno de Epitacio Pessôa a valiosa cooperação do ministro João Pessôa. [...] o edificio foi iniciado pela administração do dr. Accacio Pires. A planta é devida ao dr. Juliano Moreira, grande mestre da psychiatria brasileira. (A União, 10/05/1927).

O hospital foi entregue no governo de João Suassuna que atribuiu o gasto de mais de 200 contos com as instalações do hospital. Ainda sobre a fundação do Hospital-Colônia que prometia um lugar específico para tratar a loucura, o então Presidente da Parahyba, João Suassuna, apresenta suas considerações acerca da inauguração do hospital, no relatório apresentado no ano de 1928: "A Parahyba recebeu com os maiores aplausos a inauguração desse estabelecimento, a cuja construção está ligado por carinhoso interesse o nome do abnegado conterrâneo a quem hoje entrega os seus destinos".

O dia 23 de junho deve ser relembrado nesta casa com especial carinho. Assinala a remoção dos loucos para a Colonia de Alienados, cuja inauguração vale por um título de alta beneverencia 
para o atual governo. Sabe V. Exc. do quadro dantesco dos loucos depositados nas prisões, sem tratamento apropriado, a se devorarem na furia da moléstia; e bem pode calcular do allivio ora desfructado pela administração desta casa, dantes sem tranqüilidade, pela falta de recursos para proporcionar a tão infelizes criaturas um relativo conforto. (1928, p. 59).

Com a fundação dos hospitais, a partir da psiquiatria, passou-se a naturalizar o fato que era preciso trancafiar os loucos. Louco que não correspondia a uma ameaça à sociedade era aquele que se encontrasse internado, controlado e observado constantemente. Não havia naturalidade em ter que se deparar com eles nas ruas. Sadio era poder-se promover a reclusão total deles. Reclusão em locais apropriados, para que fosse possível, quem sabe, regenerá-los através do internamento. Nota-se que a loucura passa a ser vista como necessária de tratamento e, portanto, do saber médico.

O internamento passou a ser "[...] lugar de cura, não mais o lugar onde a loucura espreitava e se conservava obscuramente até a morte, mas o lugar onde, por uma espécie de mecanismo autóctone, se supõe que ela acabe por suprimir a si mesma" (FOUCAULT, 2005, p. 433).

Concomitantemente, o século XX vê surgir uma nova categoria de doente, o doente mental, e uma nova ciência que os objetificava: a psiquiatria.

Enquanto os hospitais funcionavam como uma cidade perfeita para abrigar os loucos, perfeita se tornava a cidade aos olhos da elite e dos que acreditavam que extinguir os loucos, os mendigos, as prostitutas e os menores do seu cotidiano era o objetivo maior que deveria ser alcançado pela mesma no início do século XX.

[...] O espaço asilar deveria ser uma cidade perfeita, transparente, racional e moral, em que a loucura pudesse ao mesmo tempo aparecer e ser abolida. Aparecer como uma verdade não só do louco, mas do homem, e ser superada pela força da racionalidade reinante na organização e no funcionamento do asilo (PELBART, 1994, p. 46).

\section{Considerações finais}

Através desta pesquisa foi possível observar as mudanças na forma de tratar a loucura na cidade da Parahyba do Norte, desde o momento em que era considerada causadora de desordens e tida como incômodo para a sociedade, até o momento em que passou a ser medicalizada. Ou seja: do período em que os loucos eram colocados na Cadeia Pública, em hospitais gerais como a Santa Casa de Misericórdia, no asilo Sant'Anna para alienados, até a internação em 1928 no Hospital-Colônia Juliano Moreira.

A princípio, a cadeia pública foi a instituição que mais absorveu em suas celas esses indivíduos. Percebe-se que a falta de um estabelecimento específico para tratamento dos loucos, ocasionou seu encerramento em várias outras instituições. Durante a pesquisa, não se obteve acesso aos relatórios da Cadeia Pública, além dos relatórios que foram publicados em jornais e apresentados aos presidentes de Estado. Nesse caso, não foi possível analisar as práticas empregadas dentro dessa instituição com relação aos loucos, mas se pode apontar que eram encarcerados como os demais detentos.

Em relação à Santa Casa, as condições dos loucos eram em locais inadequados e junto com outros doentes. Os administradores reclamavam da presença incômoda dos loucos e cobravam um lugar para "despejá-los".

Outro aspecto interessante diz respeito ao asilo Sant'Anna que, embora tenha sido inaugurado para tratar os loucos, pouco foi o seu sucesso, pois era muito mais salas que serviam de depósito para os alienados que um hospital.

Portanto, ao longo das duas primeiras décadas do século $X X$, os discursos de ataque a essa instituição serviram de justificativa para a criação de um hospital, pautado pelo isolamento científico, conforme defendido pelos psiquiatras.

Nesse contexto, a fundação do Hospital Colônia Juliano Moreira, foi percebida como a luz 
da psiquiatria que traria ordem para o problema dos alienados na capital. Por outro lado, a própria estrutura e o número de leitos não foram suficientes para atender a demanda crescente de doentes, além de atender doentes de outras localidades do Estado. A Cadeia Pública ainda continuou recebendo esses indivíduos por alguns anos demonstrando, assim, a manutenção das estratégias de controle e de exclusão dos loucos na Parahyba.

\section{Fontes}

Jornais

A União. 1895, 1897,1915, 1917,1918, 1927, 1930.

Estado da Parahyba. 1891.

Diário do Estado.1919.

Correio Official. 1903.

\section{Relatórios diversos}

POGGI, João José Innoccencio. Relatorio do Provedor de Saúde da Província de Parahyba do Norte, em 11 de ago. de 1858. Parahyba, Typ. L. Parahybana, 1858. In: ROHAN, Henrique de Beaurepaire. Relatorio apresentado á Assembléa Legislativa da Provincia da Parahyba do Norte em 20 de setembro de 1858 pelo presidente. Parahyba, Typ. de José Rodrigues da Costa, 1858.

NEVES, Lindolfo José Corrêa das Neves. Relatório da Santa Casa de Misericórdia de Parahyba, 1862 In: LIMA, Francisco D’Araujo. Relatorio apresentado á Assembléa Legislativa Provincial da Parahyba do Norte, no dia 31 de maio de 1862, pelo presidente. Parahyba, Typ. de J.R. da Costa, 1862.

Relatório do Provedor Dr. José Ferreira de Novaes, 02 de julho de 1925. apud SILVA FILHO, Edivaldo Brilhante. História da Psiquiatria na Paraíba. João Pessoa: Santa Clara, 1998.

LEAL, Walfredo. Relatório do Presidente de Estado. Parahyba do Norte, 1906.

PINTO, João Pereira de Castro. Relatório do Presidente de Estado. Parahyba do Norte, 1913.

SUASSUNA, João. Relatório do Presidente de Estado. Parahyba do Norte, 1928.

Leis

Edificações. Lei $243, \S 1^{\circ}$ e $2^{\circ}$." Collecção das Leis Provinciaes da Parahyba do Norte. Parahyba do Norte: Typ. J. R. da Costa, 08/10/1866.

\section{Referências}

ARAÚJO. Edna Maria Nóbrega. Uma Cidade muitas tramas: a cidade da Parahyba do Norte e seus encontros com a modernidade. Recife, 2001, 167p. Dissertação de Mestrado em História. Universidade Federal de Pernambuco. Recife, 2001

BRITO, Fátima Saionara Leandro. Andanças que cortam os caminhos da razão: as vivências insanas e a atuação da reforma psiquiátrica em Campina Grande PB. 2011. Dissertação (Mestrado). Programa de Pós-Graduação em História, Universidade Federal de Pernambuco, Recife, 2011.

CASTRO, Oscar Oliveira. Medicina na Paraíba: flagrantes da sua evolução. João Pessoa-PB: A União, 1945. 
CUNHA, Maria Clementina Pereira da. Cidadelas da Ordem: A doença mental na república. Coleção tudo é História. São Paulo: Brasiliense, 1989.

FOUCAULT, Michel. Microfísica do Poder. 8. ed. Rio de Janeiro: Graal, 1989.

FOUCAULT, Michel. História da Loucura na Idade Clássica. 8. ed. São Paulo: Perspectiva, 2005.

GOFFMAN, Erving. Manicômios, prisões e conventos. São Paulo: Perspectiva, 2005.

JUNQUEIRA, Helmara Giccelli Formiga Wanderley. Doidos[as] e Doutores: A medicalização da loucura na Província/Estado da Parahyba do Norte 1830-1930. Recife, 2016, 465p. Doutorado em História Universidade Federal de Pernambuco, 2016.

OLIVEIRA, Iranilson Buriti. "Fora da Higiene não há salvação": a disciplinarização do corpo pelo discurso médico no Brasil Republicano. Mneme - Revista de Humanidades v. 4, n. 7, p. 14-29, fev./mar. 2003. Disponível em: https://www.periodicos.ufrn.br/mneme/article/view/161. Acesso em: 19 nov. 2020.

OLIVEIRA, José Rogério de. Políticas Públicas de saúde mental e reforma psiquiátrica em Pernambuco (1991 - 2001). Recife, 2008. 146p. Mestrado em História, Universidade Federal de Pernambuco. Recife, 2008.

PELBART, Peter, Da clausura do fora ao fora da clausura: Loucura e desrazão. São Paulo: 1994.

SANTOS. Leonardo Querino Barboza Freire dos. Entre a Ciência e a Saúde Pública: A Construção do Médico Paraibano como Reformador Social (1911 - 1929). Campina Grande, 2015, 254p, Mestrado em História, Universidade Federal de Campina Grande, 2015.

SEVCENKO, Nicolau. Literatura Como Missão: tensões sociais e criação cultural na primeira república. 4 ed. São Paulo: Brasiliense, 1995.

SILVA FILHO, Edivaldo Brilhante. História da Psiquiatria na Paraíba. João Pessoa: Santa Clara, 1998.

\section{Notas de autoria}

Edna Maria Nóbrega Araújo: Possui graduação em História pela Universidade Federal da Paraíba, Licenciatura em Enfermagem pela Universidade Federal da Paraíba, Mestrado em História pela Universidade Federal de Pernambuco e Doutorado em História pela Universidade Federal de Pernambuco. Tem experiência na área de História, com ênfase em História do Brasil. Atualmente é professora da Universidade Estadual da Paraíba. Pesquisa nas áreas de História Cultural, História e Gênero, História, modernidade e urbanização, História da saúde e da doença e História da Loucura. E-mail: ednanobrega06@gmail.com.

Joedna Reis de Meneses: Possui Graduação em História pela Universidade Federal da Paraíba, Mestrado em História e Doutorado em História pela Universidade Federal de Pernambuco. Atualmente é Professora da Universidade Estadual da Paraíba. Tem experiência na área de História. Ministra aulas na graduação e pós-graduação de Teoria e Metodologia da História, atuando principalmente nos seguintes temas: análise Historiográfica, Subjetividades, Corporeidades, Sensibilidades e Práticas Educativas. É Professora colaboradora do PPGH/UFCG. E-mail: joedna8@gmail.com. 
Como citar esse artigo de acordo com as normas da revista

ARAÚJO, Edna Maria Nóbrega; MENESES, Joedna Reis de. As instituições de reclusão e "controle" dos loucos na Parahyba do Norte entre 1889 e 1928. Sæculum - Revista de História, v. 25, n. 43, p. 76-92, 2020.

\section{Contribuição de autoria}

Edna Maria Nóbrega Araújo: Foi responsável neste texto pela escolha de todas as fontes citadas, tais como: leis, jornais e relatórios e contribuiu também na produção do mesmo em todas as suas etapas inclusive na leitura e debate prévio das obras que fundamentam este texto.

Joedna Reis de Meneses: Pesquisa comum desenvolvida pelas autoras nos dois últimos anos. Escrita compartilhada do texto, de maneira considerada indistinta pelas autoras. À Joedna Reis de Meneses coube a decisão da citação de outros autores.

\section{Financiamento}

Não se aplica

\section{Consentimento de uso de imagem}

Não se aplica

\section{Aprovação de comitê de ética em pesquisa}

Não se aplica

\section{Licença de uso}

Este artigo está licenciado sob a Licença Creative Commons CC-BY. Com essa licença você pode compartilhar, adaptar, criar para qualquer fim, desde que atribua a autoria da obra.

\section{Histórico}

Recebido em 15/08/2020.

Modificações solicitadas em 17/09/2020.

Aprovado em 11/10/2020. 